\title{
Construction of Embedded System Teaching and Training Platform Based on Action-oriented Method
}

\author{
Pingping Lian \\ Yantai Engineering \& Technology College \\ Yantai, P.R.China
}

\author{
Qing Sun \\ Yantai Engineering \& Technology College \\ Yantai, P.R.China \\ Ning Wang \\ Yantai Engineering \& Technology College \\ Yantai, P.R.China
}

\author{
Junli Liu \\ Yantai Engineering \& Technology College \\ Yantai, P.R.China \\ Chengjin $\mathrm{Yu}$ \\ Xiamen Whatsun Technology Co., Ltd \\ Xiamen, P.R.China
}

\begin{abstract}
China is in a crucial period of industrial transformation and upgrading. Modern apprenticeship training talents for industry transformation and upgrading, is conducive to enhance core competitiveness of enterprises, promote development of modern industry, and has great significance for accelerating transformation and upgrading of industry in China. This paper focuses on the research of teaching reform of embedded system course in higher vocational colleges under modern apprenticeship, and put it into practice. Traditional embedded system teaching in higher vocational education focuses on theory teaching which leads to a poor teaching result. This paper studies the characteristics of higher vocational students and puts forward teaching should be geared to the needs of higher vocational students, achieving teaching students in accordance with their aptitude. In teaching this article uses the action-oriented teaching method. This method is project-driven centered combined with a variety of other teaching methods. With various teaching mediums the method has the characteristics of higher vocational education. The article adopts new style processor, builds a new teaching platform of embedded system, updates teaching knowledge, and proposes a direction and stage divided teaching approach in accordance with major emphasis and technical difficulty. It designs 49 ARM practice teaching projects corresponding to different directions and stages, and lays stress on improving students' ability to utilize ARM technology for innovation comprehensively. This platform also can be used for employee skill training of related enterprises.
\end{abstract}

Keywords-Application of Action-oriented Teaching Method; Teaching Project Design of Embedded System; Direction and Stage Teaching; Teaching Reform and Practice under Modern Apprenticeship

\section{INTRODUCTION}

Embedded system is computer system designed and manufactured for particular application. As an important role in national economy it is widely used in the fields of Internet of things, mobile communication, household appliances, industrial control and medical care. The course of it has become the core curriculum of Internet of things, electronic information and communication majors. Among its various implementation technologies, ARM technology is the mainstream. Only in the year of 2014, production volume of ARM reached 120 Billion which occupied the market of intelligent mobile phone and tablet computer in $95 \%$.

Under modern apprenticeship, professional teaching is docking with industrial demand, course content is docking with occupation standard, and teaching process is docking with production process. Teaching of professional courses is the basis of effective implementation of modern apprenticeship, and also a powerful guarantee for talent training quality. As one professional core course, embedded system course's teaching research is helpful to push the pilot and development of modern apprenticeship on majors of the Internet of things, electronic information and others, and has very important significance.

However, current domestic teaching practice of embedded system course is relatively backward. There are many deficiencies. (1) Not characterized for higher vocational education with few teaching practice projects. Currently embedded system teaching in vocational colleges mostly adopts theory-centered teaching methods from undergraduate colleges with few practices and equipment. However, the weak foundation and low learning ability characteristics of vocational students determine that higher vocational embedded system teaching cannot adopt traditional teaching method of undergraduate colleges. According to the characteristics of higher vocational students, an innovative higher vocational characteristic method in embedded system teaching is needed to be created for achieving training goals and job demands. (2) Knowledge of teaching is outdated. Embedded system is developing fast, however most of existing embedded system 
teaching still stay in the platform of ARM7 processor. This leads to disjoint between students' learning and production practice, and dissatisfies job demands. (3) Knowledge of project modules in practice teaching is isolated, having no connections. In current embedded system teaching practice of higher vocational education, isolated teaching and experiment method for each module is adopted. Students cannot connect multiple modules and apply flexibly. (4) No consider of different professional post demand and no differential design of practice projects. (5) No consider of the more contents and greater difficulty features of embedded system technology and set up practical projects by stages. Compared with domestic embedded system teaching in higher vocational colleges, foreign developed countries have adopted the action-oriented teaching method, conveying a large number of talents for the related industries, and achieved good results.

Aiming at above deficiencies, we take the mainstream ARM technology as the carrier of knowledge and carry on research on adopting action-oriented teaching method of higher vocational characteristic, updating course teaching knowledge, designing practice projects by stages and major directions, increasing the number of multiple module integration projects, and cultivating students' ability of combined application of multiple modules. This research solves above deficiencies, in line with the development trend of higher vocational education embedded system teaching reform.

Research on action-oriented teaching of embedded system course has practical significance for our college. (1) Our college is located in Yantai Development Zone, which region has a large number of embedded enterprises such as LG electronics, Foxconn and GM Dongyue automobile electronics. These enterprises need a great number of embedded technicians. However currently there is no embedded system course in our college. The research of setting up of this course can fill the blank of our college, improve students' embedded skills and raise graduates employment rate. (2) Shandong Business Institute and our college both newly build the major of Internet of things. Being one professional core curriculum, embedded system course has close influence for professional talent training quality. Carrying out embedded system teaching research is of urgency and importance for construction and talent training of the major of Internet of things. Meanwhile, cooperation between two colleges can avail themselves of their respective advantages, and achieve double win. (3) Research innovatively takes action-oriented teaching as the guiding ideology, design practice projects of higher vocational education characteristics, and change previous knowledge-based teaching mode. It can result in improving students' practical skills and selecting talents to participate in skills competition for our college. (4) Research can promote teachers' embedded system knowledge and skill ability, and develop a teaching staff of embedded system.

The study also has theoretical significance for the domestic higher vocational embedded system teaching research on aspects of teaching methods and practice project. It can help to improve advance of theoretical innovation in this field.

\section{Teaching Method and Teaching Means}

\section{A. Teaching method}

Qualities of students vary widely. Therefore Confucius proposes the teaching method called "teaching students in accordance with their aptitude". In this method, according to different requirements of students, appropriate teaching methods are taken, and different teachings are carried out. It can enable students to foster their strengths and circumvent their weaknesses in the study, and optimize the teaching effect.

Higher vocational college students are generally students who are not admitted to university in college entrance examination. They usually have poor learning ability and weak learning foundation. They are lack of interest in book knowledge. However, they have strong self-awareness, relative good hands-on ability and more interest on the actual project and practice. Project-driven teaching method is a teaching method of teachers and students working together to complete the project and mastering the knowledge and skills. It is consistent with the above characteristics of vocational students which leads it to a "teaching students in accordance with their aptitude" method and suitable for the characteristics of higher vocational students.

Project-driven teaching method includes three aspectsproject design, implementation and evaluation. It is a really innovative practice. Students can be keenly aware of fun of practical innovation in the practice, enhance enthusiasm of learning and change themselves from passive learning to active learning. They can also effectively learn project required knowledge and skills, improve knowledge and practical ability level, and foster problem analysis and solving ability. It can strengthen communications between teachers and students, and exchanges between students and students which exercise communication and cooperation ability, cultivate team spirit, and help to teaching feedback and optimization. It changes teaching from traditional teacher centered to student centered, from traditional classroom centered to training experiment centered, from traditional book centered to practice project centered. Project-driven teaching method is the key of embedded system course teaching in higher vocational colleges.

For teaching only one method is not enough. In actual practice we take project-driven teaching method as the primary method, combining with lecture method, visual demonstration method, practice method, problem inquiry method, case interactive method, situational simulation method, and group discussion method to constitute the action-oriented teaching method as the teaching method of embedded system course in higher vocational education, as shown in "Fig. 1". 


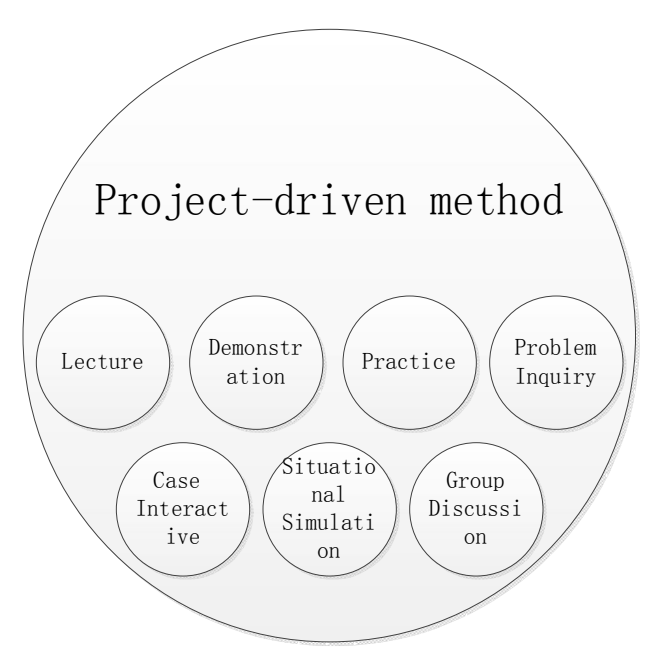

Fig. 1. Composition of action-oriented teaching method

\section{B. Teaching means}

On teaching means, we take integrated practice teaching system, source codes and circuit diagrams as the primary means, complemented with physical products, projector, multimedia video and network data as shown in Table I.

TABLE I. TEACHING MEANS

\begin{tabular}{|c|l|}
\hline \multirow{4}{*}{$\begin{array}{c}\text { Primary } \\
\text { means }\end{array}$} & $\begin{array}{l}\text { Integrated practice } \\
\text { teaching system }\end{array}$ \\
\cline { 2 - 2 } & Circuit diagrams \\
\cline { 2 - 2 } & Source codes \\
\hline \multirow{2}{*}{$\begin{array}{c}\text { Complementary } \\
\text { means }\end{array}$} & Physical products \\
\cline { 2 - 2 } & Projector \\
\cline { 2 - 2 } & Multimedia video \\
\cline { 2 - 2 } & Network data \\
\hline
\end{tabular}

\section{TEAChIng KNOWLEDGE UPDATING}

\section{A. Processor Selection}

We select ARM processor as the processor of our embedded system teaching. ARM processor technology develops rapidly and updates on an annual basis. As shown in "Fig. 2", the newest ARM processor is Cortex processor which has been widely applied to product development and actual production, such as mobile phone design, programming, pipeline assembling, and welding. However, current practice project of ARM teaching are still stay in the most low-end processor ARM7 processor. The severe disconnection between actual teaching and production job demand urgently requires us update existing teaching knowledge and lay a solid foundation for students to go to work in future.

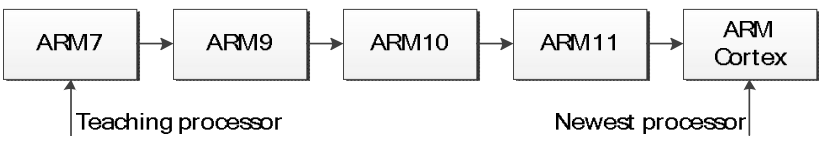

Fig. 2. ARM processor development roadmap

Although the latest ARM processor of Cortex series has powerful performance, it is complex in structure, various in function, and difficult to learn. Therefore it is not suitable to teach for beginners. Making a compromise in the balance of technology advancement, popularization degree and teaching difficulty, we have to choose a suitable ARM processor which fits teaching difficulty, conforms to the current job needs, and keeps up with technological development.

As the upgrade edition of ARM7, ARM9 processor is applied in many fields frequently. We make discussion and analysis for its suitability of teaching from three aspects.

(1) Hardware. On the processor frequency, although the highest frequency of ARM9 processor is about 200MHz, some ARM9 processor frequency can be set to as low as tens of Mega Hz. Since the processor clock frequency is chip internal resource and independent with external use, level of CPU frequency does not affect learning. On internal modules, modules of ARM9 are more but not complicated. It is easy for beginner to learn.

(2) Software. Traditional ARM7 has a slow arithmetic speed and limited resources. It cannot run embedded operating system, such as Android OS, and WinCE etc. On the contrast, ARM9 is faster, more resources integrated, and support of running of operating systems. Choosing ARM9 can achieve one-stop learning from embedded hardware to embedded software in one chip of the same type, and provide a perfect programming platform of embedded operating system which is capable of training students embedded system programming ability, meeting job skill requirements and technology development trend.

(3) Popularization and Development. Nowadays ARM9 is being used more and more widely. With rapid development of chip technology and increase of production quantity, price falling of ARM9 chip is being a trend. Currently price of some ARM9 processors targeting to traditional ARM7 market is already close to it price of ARM7. With price continuing falling, fields of ARM9 applications will be more extensive.

In conclusion, from the aspects of hardware, software, popularization and development, ARM9 is more suitable for teaching usage.

\section{B. Integrated practice teaching platform}

Learning and operation of ARM requires one integration practice teaching platform which is used to complete circuit connection, software programming, downloading, system debugging, and running. We choose EduKit-IV teaching system as our practice teaching platform of embedded system, as shown in "Fig. 3".

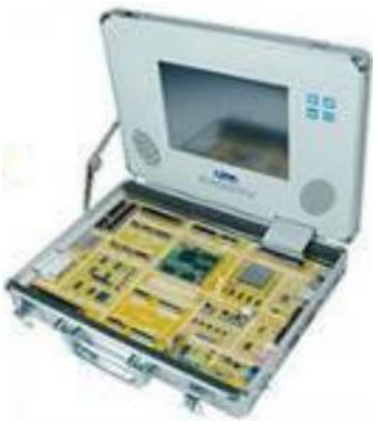

Fig. 3. EduKit-IV ARM practice teaching platform 
EduKit-IV practice teaching platform has one S3C2410 processor with built-in ARM9 kernel. It has rich hardware resources, modular applications and support of both Linux and WinCE embedded operating systems. It also provides development software compiler, simulator, Flash programmer, power adapter, and connection lines. Above all make it an adequate guarantee of design and implementation of practice projects.

\section{Design of Teaching Practice Projects}

Teaching practice project is the core of action-oriented teaching. A good practice project can cover the knowledge points and connect these points smoothly. It can take care of the level of most students and make difficulty appropriate. It also can promote students' interest and stimulate students' autonomic learning. Therefore, project design is the key to good practice of action-oriented teaching.

\section{A. Project stage setting}

The general rule of learning process is from strange to familiar which is adequately considered in our teaching design. Because ARM technology has more contents and greater difficulty, its teaching is a systematic project. Following the rule of learning we design teaching in stages from the shallow to the deep and from the simple to the complex.

We divide the practice teaching into six stages including basic practice, improvement practice, comprehensive practice, open practice, enterprise apprentice practice, and skills competition according to process of teaching, as shown in "Fig. 4". We set projects of different difficulty corresponding to each stage. In basic practice stage, get familiar with the use of ARM practice teaching system, master several programming language and ARM debug process; In improvement practice stage, train to grasp the control and using method of ARM software and hardware modules; In comprehensive practice stage, integrate knowledge studied previously to carry on development of simple system prototype; In open practice stage, open training room at extracurricular time. Students can choose projects according to their interest. Each 4 to 5 of them constitute one group, in which each takes responsible for part of the work. Every group takes 3 to 4 weeks to complete a small embedded system development; In the stage of enterprise apprentice practice, as apprentices students go to enterprises to participate in actual product research, development, production and manufacturing. Through the training form of master and apprentice, master ARM skills; Finally, select outstanding students to participate in various competitions to further cultivate students' creative ability and ARM skills.

On teaching staff, in accordance with the requirements of modern apprenticeship, excellent high skill talents from cooperative enterprises are introduced to establish a teaching team composed of full time and part time teachers, as shown in "Fig. 5". Double tutor teaching is adopted in each stage. Teachers and enterprise masters jointly undertake the task of teaching.

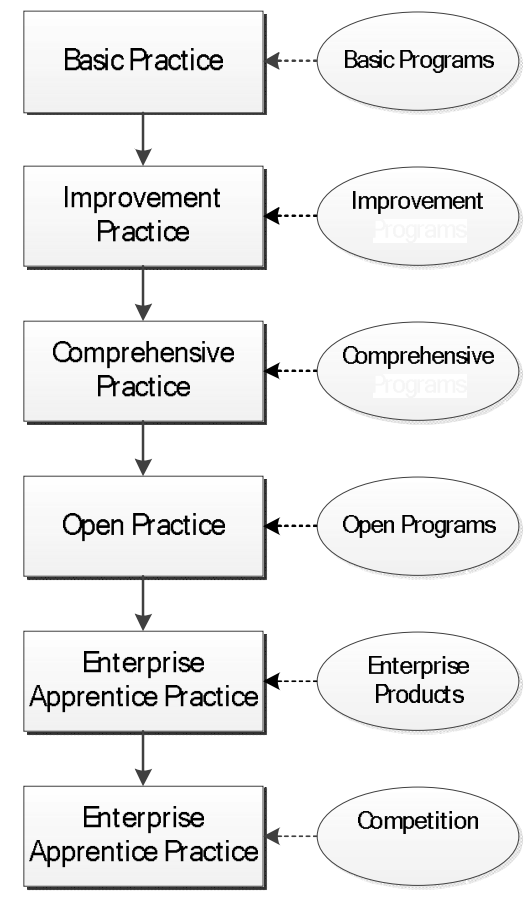

Fig. 4. Practice teaching in stages

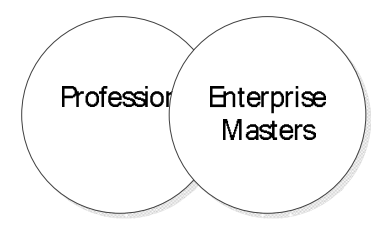

Fig. 5. Teaching staffs in double tutor teaching

\section{B. Project direction setting}

Different professional directions require different skills. However the current ARM teaching is still using the old teaching mode of single chip which faces hardware interfaces. Skills of students deviate from job requirements and cannot meet the needs of employers.

To solve above problem we highlight the application main line and set practice projects by direction to satisfy the needs of different directions and improve the efficiency of class time. Embedded system jobs are generally divided to embedded hardware jobs and embedded software jobs. Corresponding to this we divide the practice teaching to two directions, embedded hardware direction and software direction. Projects of different directions are setup to train skill talents adapting to the needs of software and hardware jobs.

\section{Multi module combined application projects}

Actual projects are basically combinations of multiple hardware interfaces, however current ARM teaching mainly targets to teaching of individual hardware module. Students are a loss what to do on how to grasp a small project.

We design some multi module combined application projects in the stages of comprehensive practice and open practice to cultivate students' ability of flexible application and interaction with each other. These projects can be developed to complete some operative simple systems which help to 
motivate students' interest and get rid of the old boring teaching mode.

\section{Project practice roadmap}

We design 49 practice projects corresponding with different teaching stages, as shown in "Fig. 6". While practice teaching tutors can flexibly select number of project and specific project according to class hour and learning of students.

\section{CONCLUSIONS}

This paper uses ARM9 processor and practice teaching system and designs 49 ARM practice projects of different difficulty which has a high practical value in teaching. ARM technology updates frequently, and its teaching equipment is of high price and complex operation. The next step of this study will focus on how to reduce the cost of ARM teaching equipment to make convenience for students to use learning.

\section{ACKNOWLEDGEMENT}

This work is funded by 2015 Young Teacher Education and Teaching Research Program of Shandong Province (No.15SDJ127), 2015 Enterprise Training and Employee Education Key Program of Shandong Province (No.2015-042), and Scientific Research Program of Yantai Engineering \& Technology College (No.2014-06).

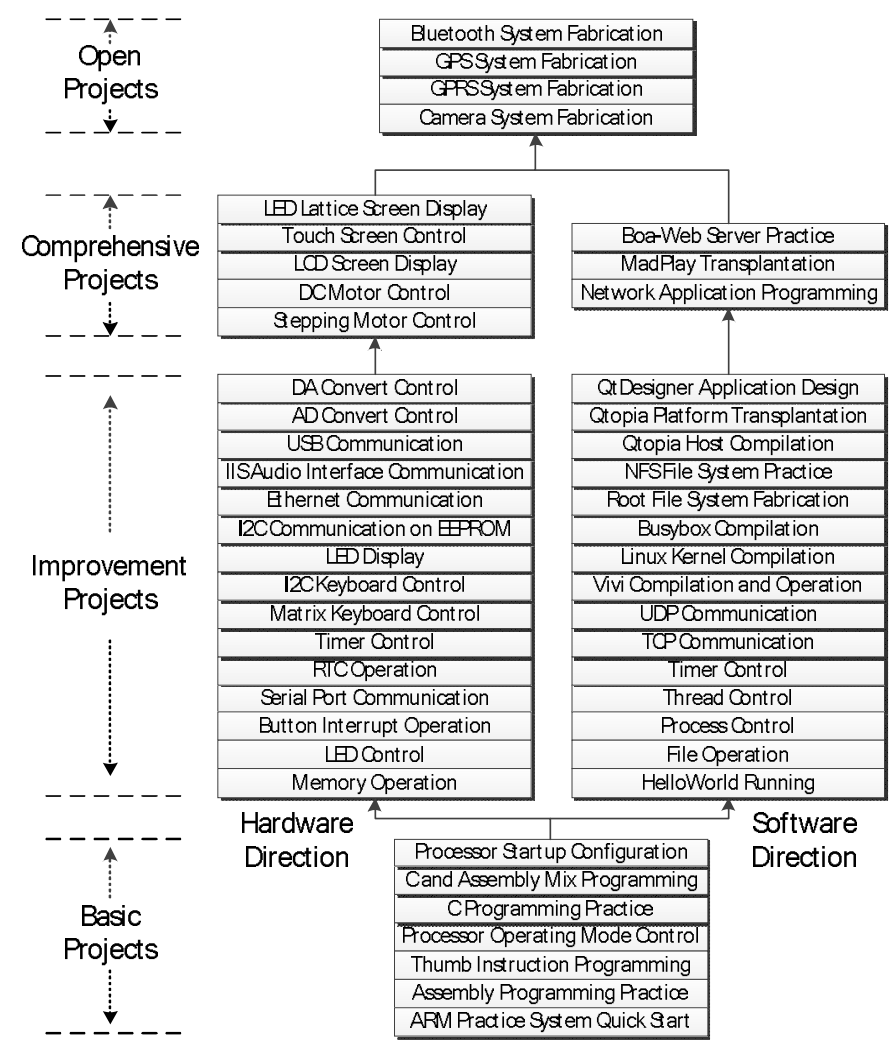

Fig. 6. Project practice roadmap

\section{REFERENCES}

[1] Steve Furber. ARM System on Chip Architecture. Beihang University Press, 2002.

[2] Andrew N.Sloss, et al. ARM System Developer's Guide: Designing and Optimizing System Software. Beihang University Press, 2005.

[3] ARM Limited. ARM Generic Interrupt Controller Architecture Specification (Architecture Version 1.0). ARM Limited, 2008. 